\title{
Story Grammar Analysis of Pre-schoolers' Narratives: An Investigation into the Influence of Task Parameters
}

\author{
Kerstin M, Tönsing and Herman Tesner \\ Department of Communication Pathology \\ University of Pretoria
}

\begin{abstract}
This study aimed at examining the influences of the parameters of the narrative task (administered to the pre-schooler) on narrative structure. Seventeen pre-school children were selected as subjects. Five narrative tasks were administered to each subject. The narratives were analysed for length and structure. Mainly two factors were found to influence the length and structure of the produced narratives; firstly, the presence or absence of a 'model' on which the child could base his/her narrative, and, secondly, the structure inherent in this 'model'. The implications of the study for clinical assessment of narrative skills as well as for further research are considered.
\end{abstract}

\section{OPSOMMING}

In hierdie studie is gepoog om die invloed van die parameters van die narratiewe taak (voorgelê aan die voorskoolse kind) op die struktuur van die narratiewe produksie te ondersoek. Sewentien voorskoolse kinders is as proefpersone gekies. Vyf verskillende take is deur elke kind uitgevoer. Elkeen van die take het die vertelling van narratiewe vereis. Alle geproduseerde narratiewe is geanaliseer ten opsigte van lengte en struktuur. Veral twee faktore het ' $n$ invloed gehad op die lengte en struktuur van die geproduseerde narratiewe; eerstens, die teenwoordigheid of afwesigheid van ' $n$ 'model' waarop ' $n$ kind sy/haar narratief kon baseer, en tweedens, die inherente struktuur van hierdie 'model'. Die kliniese implikasies van die bevindinge met betrekking tot die evaluasie van storiegrammatika asook die implikasies vir verdere navorsing word bespreek.

KEY WORDS: story grammar, pre-schoolers, narrative task, story generation, story retelling, personal experience narratives

\section{INTRODUCTION}

Since the 1980 s researchers in childhood language assessment have increasingly shifted their focus from the evaluation of discrete linguistic skills on word and sentence level to a more holistic diagnosis of longer linguistic units, such as discourse (Merritt \& Liles, 1987). Amongst other types of discourse assessment, the evaluation of narratives has gained popularity as a clinical tool. Story grammars have been developed by various authors to describe narrative structure (Mandler \& Johnson, 1977; Stein \& Glenn, 1979; Roth \& Spekman, 1986). The assumption underlying all of these grammars is that ideal stories are constructed of episodes, these being well-organised structures which describe goal-based behaviour. Story grammar models seek firstly to judge the completeness and well-formedness of an episode, and secondly to describe relations between episodes in multiple-episode narratives. One example of such a story grammar model is that described by Stein and Glenn (1979). It includes a description of story components making up an episode, as well as the relations linking these episodes together. This story grammar model and various adaptations of it have been used to analyse the structure of narratives generated by subjects from the age range of pre-school to adulthood (Merritt \& Liles, 1987; Peterson \& McCabe, 1983). Used as a clinical tool, story grammar analysis pro- vides valuable information, not only on language abilities but also on higher level processing skills. Inferences on the cognitive organisational skills of the individual have proved to be valuable sources of information to speech-language pathologists, educators and psychologists. In a pre-school setting, story grammar analysis thus seems an invaluable clinical tool for valid and accountable language screening and evaluation, as potential learning and language-learning problems can be detected at an early stage (Hemphill, Feldman, Camp, Griffin, Miranda \& Wolf, 1994).

The clinician intending to do such an analysis is faced with an array of choices pertaining to the variables of the task used for sampling story grammar skills. Scott (1988) lists and describes some of the parameters of narrative type and context. Amongst these are:

- Source: Narratives can be self-generated or retold

- Experience base: Narratives can be based on personal experiences or they can be fictional creations

- Eliciting stimuli: Different types of stimuli, such as pictures or props can be made available to the child. 
Regarding the source of the narrative, story retelling is generally believed to be the 'easier' task, as direct input of pre-structured content is given (Liles, 1993). Literature supports the notion that story generation is a more sensitive indicator of story grammar abilities. Roth and Spekman (1986), for example, found significant differences between the story grammar abilities of language-learning disabled subjects and subjects with normal language ability as displayed during story generation tasks.

Research by Peterson and McCabe (1983) suggests that narratives based on personal experiences, contain more story structures and more mature ones than fictional narratives, especially where younger children are concerned. They propose that real events need less mental ordering and may have been reported before, which leaves children to devote their attention to structural organisation of the narrative. However, children exposed to traditions of story. telling have been shown to generate well-structured fictional narratives (Alant, Tesner \& Taljaard, 1993; KayRaining Bird \& Kluppel-Vetter, 1994). Differences between the structural complexity of personal experience narratives as opposed to fictional narratives thus remain to be researched within given populations.

The types of stimuli used in eliciting fictional narratives in pre-schoolers differ with regard to the amount of structure inherent in the stimulus, and its potential effect on the organisation of the story construction. Puppets, for example, do not provide the child with any structure while producing a story. A single action picture provides a medium amount of structure as the setting, the potential story characters and an event are given. A sequence of related pictures gives a high degree of structure. Research findings on the influence of media input on story retelling varies. In some instances visual stimuli augmenting the audio-input has been shown to aid recall, (Liles, 1993) while others report an opposite effect (Schneider, 1996). Different effects of the use of props during presentation of the story on the one hand versus recall of the story on the other hand are also issues that have not been fully researched in the pre-school population. Insufficient and controversial data thus exists regarding the various methodological issues involved in evaluating story grammar abilities in pre-schoolers - be it the source of the produced narrative (generated versus retold), the experience base of the narrative (personal experience versus fiction) and/or the type of stimuli used for each task. This study therefore aims to address the following questions:

- Does a story grammar analysis of pre-schoolers' narratives elicited under various sampling conditions indicate structural similarities of productions across task?

- Are there differences in productions - correlated to these. parameters of sampling - that have practical implications in terms of clinical assessment?

\section{METHOD}

\section{.}

AIM

The aim of this study was to investigate how preschoolers' use of story grammar is affected by the following parameters of the narrative task: the experience base, the source and the eliciting stimuli. Sub-aims included the description of structural characteristics (length and story grammar parameters) of narratives elicited under five different sampling conditions, and examining possible correlations and differences between them.

\section{DESIGN}

A cross-sectional quasi-experimental design was chosen. Children's use of story 'grammar was measured in five tasks. Correlations between the sampling parameters and the structural properties of the produced narratives were then established.

\section{SUBJECTS}

A non-random convenience sample of seventeen subjects was drawn from two nursery schools. Thirteen children attended the preparatory class of an English nursery school in an affluent area, while a further four children were nonrandomly selected from the preparatory class of an English-medium nursery school in a less affluent area of the same town. The latter four children were intentionally chosen on the basis of their background; their teacher described them as coming from lower socio-economic backgrounds and disrupted families. Although a comparison between the two test populations was not the aim of the study, a varied test population might promote a richer description of the phenomena (Peterson, 1994). The age range displayed by the subjects ranged from 4 years, 8 months to 6 years, 4 months, with a mean age of 5 years, 6 months. All subjects had normal vision and hearing and had not received speech/language intervention before. The home language of all the children was English. Eleven boys and six girls participated. In order to gather information on the subjects' exposure to stories and the story reading practices of their care-givers, a questionnaire was filled in by a care-giver of each of the subjects. From the results it seemed that all subjects were exposed to stories from books and from television.

\section{MATERIAL}

\section{Task 1: Personal experience narratives}

A 'conversational map' based on McCabe and Rosenthal Rollins's guidelines (McCabe \& Rosenthal Rollins, 1994) was devised in order to elicit personal experience narratives from the subjects. The adapted 'conversational map' consisted of six personal anecdotes followed by various sets of probe questions. Each set of questions consisted of one or two closed questions to establish whether a theme would be successful, followed by an open question which invited the actual telling of the narrative.

\section{Task 2: Story generation with puppets}

Five cardboard puppets, as well as three cardboard pictures of objects were used.

\section{Task 3: Story generation with a picture}

A magazine picture was chosen as a stimulus for this story generation task. It depicted a setting and potential story characters involved in a problem-solving attempt.

Story retelling: Task 4 (Puppet Condition) and Task 5 (Picture Condition) 
Material used for the retelling tasks consisted of two model stories as well as the visual material used for each story. In order to limit variables as much as possible, care was taken to ensure that the model stories corresponded to each other in length, structure and content. The first model story (used in Task 4) consisted of 251 words and 41 clauses; while the second model story (used in Task 5) consisted of 255 words and 41 clauses. The structure of each story was analysed according to Stein and Glenn's story grammar analysis (Stein \& Glenn, 1979). 46 and 47 story components were identified in the two stories respectively. Both stories were classified as multiple structure episodes. A set of eight cardboard puppets as well as five cardboard pictures of objects were used for the first retelling task (Task 4). A sequence of eight hand-drawn and coloured-in pictures was used for the second retelling task (Task 5).

\section{PROCEDURE}

A pilot study was undertaken in order to determine whether the material used during the narrative tasks was age-appropriate, and whether elicitation procedures and analytical procedures were successful. The procedures for the main study were then adapted based on the results of the pilot study.

\section{Pre-recording procedures:}

The researcher spent an average of two hours spread over three to four days per week for three consecutive weeks to establish rapport with the children.

\section{Recording procedures:}

Each child completed all five tasks in one sitting and was tested individually in a quiet venue at the nursery school by a single examiner. Generated and retold stories were audio-recorded by means of a Tandberg Audio Tutor TAT 771 tape recorder and TDK IECI/Type I D 60 cassettes. The production and retelling tasks were presented in this order to eliminate the possibility of the model stories influencing the child's generated stories. No time limits were imposed on any of the tasks.

\section{Task 1: Collection of personal experience narratives}

The conversational map was used. The researcher engaged in conversation with the subject and inserted the various personal anecdotes after each of which were inserted two or more questions/prompts inviting subjects to share their experience. While the subject was narrating, merely neutral sub-prompts such as the exact repetition of a portion of the child's utterance, vocalisations ('ah!', 'hmm', 'oh') and neutral questions (such as 'And then?') were used. At least five narratives were collected per subject.

\section{Task 2: Story generation with puppets}

Subjects were presented with the cardboard pictures and puppets. The following instructions were given: 'Use these pictures to make up your own story. Use as many of the pictures as you like; you need not use all the pictures. Think about your story first, and tell me when you are ready.' While subjects were narrating, once again only neutral subprompts were given.

\section{Task 3: Story generation with an action picture}

Subjects were presented with an action picture. They were given the following instructions: 'Look at this picture carefully. Make up a story about it. Your story need not be only about the picture, you can tell me about what happened before and after as well. Think about your story and tell it to me when you are ready.'

\section{Tasks 4 and 5: Story retellings}

Subjects were given the following instructions before both retelling tasks: 'I am going to tell you a story now. Listen carefully. After I've finished, I want you to tell the story back to me.' Cardboard puppets and pictures of objects were presented to the subject as the first model story (Puppet Condition) was narrated by the examiner. Following the presentation, the examiner gave the following instructions: 'Now you tell me the story.' The cardboard puppets and pictures were given to the subject to use during his/her retelling. During narration of the second model story (Picture Condition), the subject was presented with a sequence of eight pictures depicting the story episodes. The pictures were presented one by one while the examiner narrated the model story. The subject was then prompted to retell the story with the same instructions as for Task 4. The pictures were not available to the subject during the retelling task.

\section{PROCESSING OF DATA}

\section{Transcription}

As the researcher was interested in the structural properties of the children's narratives, transcription of the taped narratives focused on the content of the child's utterances. Repetitions of words and vocalisations were not transcribed.

\section{Analysis}

Quantitative and qualitative data was obtained and analysed by means of descriptive statistics - consisting of means, percentages and relative frequency measures, expressed as percentages (Caswell, 1995). For narratives to be included in the analysis they had to consist of a minimum of two statements. All included narratives were analysed for length as well as for their structural properties. Each narrative was segmented into statements, defined as main or subordinate clauses. The criteria governing the selection of statements for the analysis are given in Appendix 1. A word count was done for each of the elicited narratives. The words of all statements that were included in the analysis were counted. No fillers, repetitions or false starts were counted. A statement count was also done for each of the elicited narratives. Statements were then classified into story components. Descriptions of these components can be found in Appendix 2. After statements were coded, so-called structural patterns (Peterson \& McCabe, 1983) were identified, by which narratives were divided into sequences (non-goal-based) or episodes (goal-based). Descriptions of these structural patterns can be found in Appendix 3 . The data analysis consisted of comparing the narratives elicited by each of the five'tasks with respect to the following:

- average length of narratives as calculated by word- and statement counts 
- average length of structural patterns: basic structural patterns and complete episodes

- frequency with which the 11 structural patterns occurred.

\section{Scoring reliability}

Eighteen $(10 \%)$ of the elicited narratives were independently rated by a second examiner, yielding a point-to point agreement of $86 \%$ for the assignment of structural patterns to the narratives. Point-to-point agreement was $85 \%$ for classifying statements into story components.

\section{RESULTS AND DISCUSSION}

\section{LENGTH}

Analyses pertained to the average length of narratives as well as to the average length of complete episodes. Average length was determined by the mean number of words, the mean number of statements and the mean number of basic structural patterns across all narratives produced for a specific task. The results are summarised in Table 1 . While stories generated in response to the picture (Task 3 ) were similar in length to story retellings (Tasks 4 and 5), personal experience narratives were significantly shorter on average. Stories generated in response to puppets were significantly longer on average.

The experience base of the narrative clearly influenced length, as can be established when comparing personal experience narratives (Task 1) and generated stories (Tasks 2 and 3). Personal experience narratives, by the nature of the prompts, tended to be accounts focusing on usually one dramatic incidence, with between one and three prominent characters. More than half of these narratives $(55,36 \%)$ consisted of only one structural pattern. Usually no extended recounts of preceding or following events was given. In contrast, the stories generated in response to puppet and picture stimuli were more elaborate narratives, including more detailed descriptions of settings, initiating events, attempts etc. Orsolini (1990) remarks on the more formal and elaborate style encountered in children's fantasy narratives when compared to their 'real' (personal experience) narratives. He ascribes this difference to the fact that per- sonal experience narratives are aided by shared knowledge between speaker and listener, conversational co-operation and memory of the events narrated. As a result, the process of conveying pieces of verbal information is facilitated, and the speaker is allowed certain 'short-cuts' in his language use. Fictional narratives, however, require extension of discourse topic without these scaffolds, necessitating more detail and descriptions and more formal language use (Orsolini, 1990). Generated stories necessitate a great deal of planning, both of semantic content and of so-called 'macro-' and 'micro-units' (i.e. story grammar and sentence grammar respectively) (Orsolini, 1990). However, it seemed that the subjects of this study were not always aware of this demand, and spontaneously launched into all narrative tasks without much pre-consideration to either structure or content. If the narrator was offered some form of structured 'model' (be it a highly structured picture, a personal experience that can be retrieved from memory or a model story) this lack of planning could be compensated for by resorting to the structure inherent in this 'model'. However, if no structured 'model' was available (as was the case for stories generated in response to the puppet stimuli), this lack of planning resulted in long, rambling, unfocussed narratives as were produced for Task 2.

When considering the two story generation tasks (Tasks 2 and 3 ), the degree of structure inherent in the stimulus influenced length. Puppets, being unstructured stimuli, resulted in elaborate, yet somewhat rambling stories. Subjects narrated consecutive actions and events, without one main goal or focus within the narrative. The single action picture, in contrast, strongly suggested a central incident for the narrative - the retrieval of a kite. Only three subjects extended the content of their narrative beyond this incident.

Regarding the retelling tasks, stories retold with the use of puppets (Task 4) were found to be longer on average than those retold without visual support material (Task 5). These results were in agreement with the research review by Liles (1993), who tentatively concludes that children respond favourably to visual support during retelling.

\section{STORY GRAMMAR ANALYSIS}

After coding statements into story grammar components, structural patterns were identified, and the relative fre-

TABLE 1: Word and statement counts of narratives produced for Tasks 1 - 5

\begin{tabular}{|l|c|c|c|c|c|}
\hline & $\begin{array}{c}\text { Task 1: } \\
\text { Personal } \\
\text { experience } \\
\text { narratives }\end{array}$ & $\begin{array}{c}\text { Task 2: } \\
\text { Story } \\
\text { generation: } \\
\text { Puppets }\end{array}$ & $\begin{array}{c}\text { Task 3: } \\
\text { Story } \\
\text { generation: } \\
\text { Picture }\end{array}$ & $\begin{array}{c}\text { Task 4: } \\
\text { Story } \\
\text { retelling: } \\
\text { Puppets }\end{array}$ & $\begin{array}{c}\text { Task 5: } \\
\text { Story } \\
\text { retelling: } \\
\text { Picture }\end{array}$ \\
\hline Sum of narratives produced & 112 & 17 & 17 & 17 & 17 \\
\hline Mean number of words per narrative & 58.5 & 232.53 & 95.76 & 11.76 & 90.29 \\
\hline $\begin{array}{l}\text { Mean number of statements } \\
\text { per narrative }\end{array}$ & 9.67 & 39.53 & 15.41 & 19.41 & 4.14 .06 \\
\hline $\begin{array}{l}\text { Mean no. of basic structural patterns } \\
\text { per narrative }\end{array}$ & 1.69 & 7.42 & 2.41 & 4.65 \\
\hline $\begin{array}{l}\text { Relative frequency of narratives consis- } \\
\text { ting of a single basic structural pattern }\end{array}$ & $55.36 \%$ & $11.76 \%$ & $29.41 \%$ & $0.00 \%$ & $11.76 \%$ \\
\hline
\end{tabular}


quency of the 11 types of structural patterns (see Appendix 2 for definitions) was calculated for each of the five tasks. Hierarchies of structural patterns as a function of task were established. Data was then grouped to allow for comparisons of the following parameters:

- Relative frequency of structures with internal causal links (i.e. all structures except for descriptive and temporal sequences)

- Relative frequency of complete episodes (i.e. all abbreviated, simple, interactive and complex episodes, as well as episodes with multiple plan application)

- Relative frequency of complex episodes.

Tasks were compared by grouping them into hierarchies. Results are summarised in Table 2. Parameters of the narrative task clearly influenced the narrative structure as described by these structural patterns. Narratives based on personal experiences (Task 1) contained more complex episodes than the fictional narratives (Tasks 2 and 3). In this regard, the results confirmed Peterson and McCabe's (1983) suggestion that narratives about personal experience may be more complex than fictional narratives as the child reports events already ordered. The demand on creativity and imagination is thus less, resulting in more time being devoted to the structuring of the narrative (Peterson $\& \mathrm{McCabe}, 1983)$. Another factor that might have contributed to the finding that personal experience narratives were better-structured than generated stories, could be the motivation underlying each task. Narrating a personal experience is usually a self-initiated attempt to share an important event (Heath, 1986). The narrator must structure his/her account well in order to facilitate the comprehension of the listener. In narrating fictional stories, listener comprehension is, of course equally important. However, fictional stories do not emanate from the desire to share an important event - pre-schoolers in this study seemed to be less concerned with the listener's comprehension of their fictional narratives, possibly resulting in poorer structure. Furthermore, fictional narratives are only indirectly based on the causality of the real world (i.e., the relationship between cause and effect), while personal experience narratives have a direct model which engenders causality - promoting a causal structure.

Generated stories differed in structural complexity according to the stimulus material used. The picture stimulus (Task 3 ) elicited more complex and complete narratives than the puppets (Task 2) which could be attributed to the greater amount of structure inherent in this stimulus (Hedberg \& Stoel-Gammon, 1986). The picture portrayed goal-based behaviour, thereby strongly suggesting to the child a single-episode narrative. Puppets, on the other hand, have no inherent structure, and thus placed high demands on the narrator with regard to content. From the results it seemed clear that the pre-schoolers were not yet skilled in structuring narratives under such conditions where demands on content were high (Orsolini, 1990).

The influence of eliciting stimuli on the retold stories was more difficult to determine - retelling tasks differed by more than one variable, namely the type of stimulus used during presentation and availability of visual support material for retelling. Both variables or the combination could be responsible for the difference in complexity. Stories retold for the Picture Condition (Task 5) showed greater structural complexity than stories retold for the Puppet Condition (Task 4). The use of the puppets during presentation of the model story (Task 4) might have given less visual structure to the story than the sequence of eight pictures (Task 5). Children's encoding of the story structure might thus have been enhanced by the picture sequence more than by the use of puppets, resulting in more complex retellings. However, it is important to note that the children remembered less story information and fewer episodes for Task 5 , but structured their retellings better. This led to a hypothesis concerning the size of the memory load for each of the retelling tasks. The notion that story grammar abilities directly guide the encoding, remembrance and integrity of recall of a model story is wide-spread in the literature (Mandler \& Johnson, 1977; Page \& Stewart,.1985; Montague, Maddux \& Dereshiwsky; 1990). It is therefore hypothesised, that a recall task with a greater memory load necessitates a greater reliance on story grammar abilities than a task which has a lesser load on memory. The lack of visual stimuli during the activity of retelling the story for the Picture Condition (Task 5) is hypothesised to increase memory load, resulting in a smaller number of episodes being recalled. Simultaneously a greater reliance on story grammar due to the greater memory load resulted in better-structured productions.

Comparisons regarding the structural complexity of rètold versus generated narratives showed a clear tendency towards higher complexity in the retold stories. This result correlated well with research findings on narrative generation and retelling of older children with and without language impairment (Merritt \& Liles, 1989). It seems that a model story serves as a guide-line which facilitates the

TABLE 2: Hierarchy of tasks regarding relative frequency of structures with internal causal links, complete episodes and complex episodes

\begin{tabular}{|c|c|c|c|c|c|}
\hline \multicolumn{2}{|c|}{$\begin{array}{l}\text { Relative frequency of structures } \\
\text { with internal causal links }\end{array}$} & \multicolumn{2}{|c|}{$\begin{array}{l}\text { Relative frequency of complete } \\
\text { episodes }\end{array}$} & \multicolumn{2}{|c|}{$\begin{array}{l}\text { Relative frequency of complex } \\
\text { episodes }\end{array}$} \\
\hline Task 5 & $80.76 \%$ & Task 3 & $66.67 \%$ & Task 5 & $40.74 \%$ \\
\hline Task 3 & $78.79 \%$ & Task 5 & $62.86 \%$ & Task 4 & $29.27 \%$ \\
\hline Task 4 & $76.47 \%$ & Task 4 & $51.22 \%$ & Task 1 & $17.76 \%$ \\
\hline Task 1 & $70.75 \%$ & Task 1 & $50.66 \%$ & Task 3 & $11.43 \%$ \\
\hline Task 2 & $58.76 \%$ & Task 2 & $33.33 \%$ & Task 2 & $6.31 \%$ \\
\hline
\end{tabular}


structural organisation of a child's narrative. One reason could be that a retelling task demands less imagination and creativity than a generation task, as the model story presented the retelling task provides the content of the story. One might argue that, while narrative retelling reduces the demands on creativity and imagination, it certainly makes demands on memory. However, literature supports the notion that remembering story details and structuring these into a narrative are closely interrelated processes (Mandler \& Johnson, 1977). In the same way as structuring abilities were argued to aid in the encoding and remembrance of past events, structuring abilities should aid in both the process of encoding (and therefore remembering) the story, as well as in the process of retelling the story. The same type of relationship does not necessarily exist between creativity (needed to generate a story) and structuring abilities. Whereas demands on structuring and creativity therefore seem to be cumulative, competing for cognitive resources, demands on memory and structuring rely on the same cognitive mechanism.

\section{CONCLUSION}

While assessment of narrative abilities has been shown to be a valid method of sampling language and higher-level processing skills, the pragmatic nature of the task makes the narrator's performance susceptible to the influence of methodological variables of the elicitation task (Liles et al, 1995). In this regard, researchers (such as Johnson, 1995; Schneider, 1996) alert to the need for in-depth studies of children's narrative discourse, not only across variables such as children's age, cultural, ethnic and socio-economic backgrounds but also across different sampling conditions. Within limits, this study has aimed to address the latter issue. It is thus proposed that, bearing certain methodological constraints in mind, the results contribute towards a better understanding of the relationship between the narrative task parameters and the narrative produced by children of pre-school age. In particular, the results illuminate the influence of the methodological parameters of the experience base of the narrative, the source of the narrative and the eliciting stimuli used during the task on the length and structure of the product. In so-doing, some clinical guidelines for assessment of pre-schoolers' narrative skills can be proposed. All five story tasks elicited extended discourse, which could be analysed according to a story grammar scheme. Several factors, however, might influence the clinician's choice of task in a given situation.

\section{NARRATIVE LENGTH}

Stories generated in response to puppets were found to be longest, while personal experience narratives were rather short on average. While length is an asset when certain linguistic parameters in the realm of semantics or syntax need to be assessed (Merritt \& Liles, 1989), transcription is laborious.

\section{STRUCTURAL ORGANISATION}

Pre-schoolers' narrative productions benefited (with regard to structural organisation) from highly structured stimuli such as the action picture or the model stories. Stimuli with little inherent structure (such as the puppets) resulted in less complex and well-organised productions.
This finding was related to the higher demand on creativity that 'unstructured' stimuli place on the narrator (Orsolini, 1990). Pre-schoolers with a language impairment, who can be expected to have difficulties with both creativity and structuring of discourse (Liles et al, 1995), are likely to be overtaxed by tasks requiring both skills. However, creativity associated with 'unstructured' stimuli allows for observation of other variables in the children's productions, for example the theme chosen, the character details (quantity of characters, description of these), and the originality of the story line.

\section{EASE OF ELICITATION}

In the present study, it was found that personal experience narratives were more readily told by the children. The informal, conversational method of eliciting narratives allowed the clinician to establish rapport with the child. However, relating personal experiences to adults is not a common practice in all cultural groups (Heath, 1986). Children from different cultural backgrounds might therefore not display the same spontaneity as the present subjects when prompted to share personal experiences.

\section{RELEVANCE OF THE TASK FOR A SCHOOL-READI- NESS EVALUATION}

As narrative abilities are strong indicators of predicted school success (McCabe \& Rosenthal Rollins, 1994), assessment of story grammar abilities should form part of a schoolreadiness evaluation. In selecting a narrative task for such a purpose, the clinician should ensure its predictive validity (Neuman, 1997). The ability to structure decontextualised discourse is one of the prerequisites for the acquisition of literacy. While the organisational skills required for relating a personal experience are reminiscent of pragmatic conversational competence, story generation and retelling require structuring of more decontextualised discourse. The latter two tasks might thus be more representative of the cognitive academic language demands placed on the child in the school context.

Apart from clinical implications, results add to the growing body of research data on children's narrative abilities and can direct further research. Individual differences' and the variability of performance within one individual could be researched by comparing performance of individual children across tasks. The influence of a child's exposure to narratives on his/her story grammar abilities could be determined with more extensive surveys, field observations and interviews with teachers and care-givers. A subject pool controlled for gender could illustrate the differences between the story grammar abilities of boys versus girls. The validity of the present story grammar model for analysing stories told by members of non-western cultures needs to be determined as a prerequisite for accountable intervention. A longitudinal study could illustrate the relationship between a child's story grammar abilities and his/her consequent school performance. Such data is the prerequisite to including the assessment of narrative abilities.in a schoolreadiness evaluation.

The study of children's narrative ability is an exciting and expanding field of research, of interest to many professionals such as educators, clinical and cognitive psychologists, anthropologists, linguists and speech-language pathologists. Studies such as the present one can aid in ex- 
panding the knowledge of narration and narrative development. Ultimately, the establishment of a comprehensive set of norms for narration might be achieved, although this task is a formidable one in view of the many contextual influences on narrative ability (Johnson, 1995; Schneider, 1996). However, even without a comprehensive set of norms, understanding the variables that influence a child's narrative production should enable clinicians to conduct valid and accountable assessments of narrative skills and should direct their efforts in intervention.

\section{REFERENCES}

Alant, E., Tesner, H. \& Taljaard, E. (1993). Narrative performance in context: Analysis and implications within a South African context. Child Language Teaching and Therapy, 8(2), 188-204.

Caswell, C. (1995). Success in statistics. John Murray Ltd.: London.

Heath, S. B. (1986). Taking a cross-cultural look at narratives. Topics in Language Disorders, 7(1), 84-94.

Hedberg, N. L. \& Stoel-Gammon, C. (1986). Narrative analysis: clinical procedures. Topics in Language Disorders, 7(1), 58-69.

Hemphill, L., Feldman, H. M., Camp, L., Griffin, T. M., Miranda, A. B. \& Wolf, D. P. (1994). Developmental changes in narrative and non-narrative discourse in children with and without brain injury. Journal Of Communication Disorders, 27(2), 107-133.

Johnson, C. J. (1995). Expanding norms for narration. Language, Speech and Hearing Services in Schools, 26(4), 326-343.

Kay-Raining Bird, E. \& Kluppel Vetter, D. (1994). Story telling in Chippewa-Cree children. Journal of Speech and Hearing Research, 37(6), 1354-1368.

Liles, B. Z. (1993). Narrative discourse in children with language disorders and children with normal language: A critical review of the literature. Journal of Speech and Hearing Research, 36(5), 868-882.

Liles, B. Z., Duffy, R. J., Merritt, D. D. \& Purcell, S. L. (1995). Measurement of narrative discourse ability in children with language disorders. Journal of Speech and Hearing Research, $38(2), 415-425$.

Mandler, J. M. \& Johnson, N. S. (1977). Remembrance of things parsed: Story structure and recall. Cognitive Psychology, 9, 111151.

McCabe, A. \& Rosenthal Rollins, P. (1994). Assessment of pre-school narrative skills. American Journal of Speech-Language Pathology, 3(1), 45-56.

Merritt, D. D. \& Liles, B. Z. (1987). Story grammar ability in children with and without language disorder: Story generation, story retelling and story comprehension. Journal of Speech and Hearing Research, 30(4), 539-552.

Merritt, D. D. \& Liles, B. Z. (1989). Narrative analysis: Clinical applications of story generation and story retelling. Journal of Speech and Hearing Disorders, 54(3), 438-447.

Montague, M., Maddux, C. D. \& Dereshiwsky, M. I. (1990). Story grammar and comprehension and production of narrative prose by students with learning disabilities. Journal of Learning Disabilities, 23(3), 190-197.

Neuman, W. L. (1997). Social research methods. Qualitative and quantitative approaches. Allyn \& Bacon: Boston.

Orsolini, M. (1990). Episodic structure in children's fantasy narratives: "Breakthrough" to decontextualised discourse. Language and Cognitive Processes, 5(1), 53-79.

Owens, R. E. (1995). Language disorders: A functional approach to assessment and intervention. Allyn \& Bacon: Massachusetts.

Page, J. L. \& Stewart, S. R. (1985). Story grammar skills in schoolage children. Topics in Language Disorders, 5(2), 16-30.

Peterson, C. (1994). Narrative skills and social class. Canadian Journal of Education, 19(3), 251-269.

Peterson, C. \& McCabe, A. (1983). Developmental psycholinguistics Three ways of looking at a child's narrative. Plenum Press: New York.

Roth, F. P. \& Spekman, N. J. (1986). Narrative discourse: Spontaneously generated stories of learning-disabled and normally achieving students. Journal of Speech and Hearing Disorders, 51(1), 8-23.

Schneider, P. (1996). Effects of pictures versus orally presented stories on story retellings by children with language impairment. American Journal of Speech-Language Pathology, 5(1),
86-95.

Scott, C. M. (1988). A perspective on the evaluation of school children's narratives. Language, Speech and Hearing Services in Schools, 19(1), 67-82.

Stein, N. \& Glenn, C. (1979). An analysis of story comprehension in elementary school children. In R. O. Freedle, Editor, New directions in discourse processing, Ablex: New Jersey.

\section{APPENDDX}

\section{Scoring procedure: Story components}

The following procedural guidelines were adapted from Peterson \& McCabe's (1983) story components, which was based on Stein \& Glenn's story grammar categories (Stein \& Glenn, 1979). If a statement met the criteria for more than one component, it was scored as both. A statement was generally not scored as more than two categories, and maximally in three, which occurred seldom. Assigning components to statements proceeded in the same manner for both generated and retold narratives. Statements that were retold from the model story were thus assigned a certain component based on the function they served within the retold story, regardless of the component which they had been assigned in the original model story.

\section{APPENDIX 2}

\section{Story grammar components}

\section{Set 1:}

Components of this set were assigned to statements within structural patterns displaying internal causal links.

1. Setting: Introductions of characters, descriptions of location or time, information on the habitual social, physical, and/or temporal context, as well as habitual actions or states.

2. Initiating event: Any natural occurrences, actions, internal events and awareness of these (e.g. pain, hunger, etc.) as well as verbalisations having some immediate result or evoking a response, internal response or attempt from a character.

3. Internal response: Internal states such as affects, cognitions, or goals, that motivated a protagonist and/ or were caused by an initiating event.

4. Response: All verbal responses of the characters to an initiating event, provided that such responses were not an expression of internal affect, cognition or goals, in which case they fell into the category of internal responses.

5. Plan: Statements specifying the character's strategy for obtaining a goal.

6. Attempt: The character's overt action(s) to obtain a goal.

7. Direct consequence: Descriptions of the character's success or failure at attaining his/her goal(s), any existing states once all attempts had failed, or any change in the sequence of events resulting from the character's attempts.

8. Reaction: How the character felt about the outcome, and verbal responses to this.

9. Result: A result was scored when an initiating event and/ or an internal response caused a change in the environment which had not been planned or intended by the character(s), and it did not result from a goal-based action from the character(s). 


\section{Set 2:}

Components of this set were assigned statements within narratives without causal links, or to general statements (which neither served a specific function nor provided setting information) occurring within a structural pattern with internal causal links.

1. Actions: These described the behaviour of the character. Included in this category were verbalisations of the character(s), such as 'He said, "Happy birthday, Lisa!"'

2. External states: This category could be described as roughly an equivalent of the setting-category, as it included all statements which described the story environment, such as introductions.and descriptions of the character(s), their physical characteristics and states (hunger, pain, tiredness) and information about the location and the temporal aspects. The character's position in space was also included in this category, for example, 'He stood next to her'.

3. Internal states: These described the internal states of the character(s), that is, affect, likes, dislikes and character traits.

4. Occurrences: These described changes in the environment and/or character which neither were character-induced nor fell into the category of internal states. Examples are: 'The car crashed' or 'He died'.

\section{APPENDIX 3}

\section{Structural patterns in order of increasing complex- ity}

1. Descriptive sequence: Descriptions of character(s), surroundings, and habitual actions without any temporal or causal relationship.
2. Temporal sequence $(t / s)$ : At least two actions and/or occurrences that were chronologically rather than causally ordered.

3. Reactive sequence $(r / s)$ : In these sequences, events, changes or conditions automatically caused other changes, but no planning or goal-based behaviour from character(s) was evident.

4. Abbreviated episode (a/e): A goal could be understood though it was inferred rather than explicitly stated.

5. Simple episode: An entire goal-based behaviour sequence was described, including a motive for action in the form of an initiating event or an internal response, an overt attempt and a direct consequence.

6. Multiple plan application: An elaboration of the simple episode where the character met with failure of his/her attempt to achieve a goal, and consequently engaged in at least one new attempt to reach the same goal.

7. Interactive episode: Two characters had (usually opposing) goals and influenced each other.

When several structures had causal links between them, they formed a complex episode. Three types of complex episodes exist:

1. Complex episode: embedded reactive sequence: A reactive sequence was causally related to an episode

2. Complex episode: embedded episode: Two episodes were causally related

3. Multiple structure episode: More than two episodes and/ or reactive sequences were causally related

Incomplete episode (/e)

These episodes lacked a direct consequence. If no consequence could be inferred, yet the character's behaviour was purposive, episodes were scored as incomplete. 